\title{
Readiness of Future Speech Therapists for Team Interaction in the Context of Inclusion
}

\author{
Anastasiia Kapliienko \\ Department of Family and Special Pedagogy and Psychology, South Ukrainian National Pedagogical University named after K. D. \\ Ushynsky, Ukraine
}

Received May 10, 2020; Revised June 22, 2020; Accepted August 10, 2020

\begin{abstract}
Cite This Paper in the following Citation Styles
(a): [1] Anastasiia Kapliienko , "Readiness of Future Speech Therapists for Team Interaction in the Context of Inclusion," Universal Journal of Educational Research, Vol. 8, No. 10, pp. 4400-4405, 2020. DOI: 10.13189/ujer.2020.081006.
\end{abstract}

(b): Anastasiia Kapliienko (2020). Readiness of Future Speech Therapists for Team Interaction in the Context of Inclusion. Universal Journal of Educational Research, 8(10), 4400-4405. DOI: 10.13189/ujer.2020.081006.

Copyright $(2020$ by authors, all rights reserved. Authors agree that this article remains permanently open access under the terms of the Creative Commons Attribution License 4.0 International License

\begin{abstract}
The modern educational paradigm is changing the approach to teacher training, including future speech therapists. Under the new conditions, the ability of a teacher to work in a team is of great importance. And in the field of inclusive education, in general, the success of tasks depends on the close interaction of all specialists. Therefore, this study is devoted to the study of the readiness of pedagogical staff (future speech therapists) to interact on the context of inclusion. The results of an experiment to analyze the awareness of future speech therapists of teamwork in an inclusive learning environment are presented. It is noticed that despite the powerful scientific and methodological arsenal of various techniques, future speech therapists are not ready for cooperation in a team. In this regard, the need to organize special work to improve the readiness of future speech therapists to work in an inclusive educational environment is emphasized. To this end, methodological ways of preparing future speech therapists to work in a team have been identified, in particular, team interaction training has been developed and tested, and according to which $85 \%$ of the experiment participants have increased their level of preparedness for team interaction in the context of inclusion from medium to high.
\end{abstract}

Keywords Speech Therapist, Inclusive Educational Environment, Team Interaction

\section{Introduction}

Ukraine is continuing the process of reforming the educational system, aimed at developing and acquiring a person's quality abilities, bringing domestic criteria to European standards.

Modern requirements for the training of specialists with higher education require fundamental changes in approaches to the educational process. One of the main tasks of modern education is to provide society with specialists who have fundamental knowledge, skills and abilities, who are able to solve extraordinary issues creatively. Qualified, productive leading specialists are the goal of education in the XXI century [15].

Taking into consideration the changes in the global educational paradigm, increased attention to the individual development of each person, recognition of the humanistic foundations of education as the most consistent with the principles of the rule of law is one of the prerequisites for the full involvement of children with impaired psychophysical development in the system of social relations, inclusive education of children with special educational needs is extremely important.

An inclusive model of education has positively established itself in European education systems. World experience in the formation and development of educational policies for the implementation of inclusive education testifies to the need to "mature" to its society, to solve legal, financial and personnel problems.

The concept of the New Ukrainian School has led to a public demand for the training of teachers who are able to adapt quickly to new conditions and to subordinate their activities to achieving effective results in working with children in an inclusive educational environment. 
At the forefront of solving this problem is the need to improve, increase efficiency and intensity of the university student's education.

Accordingly, the requirements for the training of specialists in the field of special education are changing. Due to the active introduction of inclusive forms of education in the educational process of preschools and general secondary education institutions, there is now a need for qualitative training of future speech therapists to work in new conditions. And since the success of inclusive education tasks depends to a large extent on the close interaction of all professionals, readiness for team interaction is of paramount importance.

Modern education focuses on group interaction to share experiences and ideas. Thus, student-centered learning in an interactive educational environment is the key to successful training of qualified professionals (Buletin Anjakan Bil. 5/2015, KPM).

\subsection{Research Objective}

\section{Research Questions:}

1. To what extent are students aware of the peculiarities of the activities of speech therapists in inclusion?

2. What is the level of development of team interaction skills among future speech therapists?

3. How to prepare future speech therapists for team interaction in an inclusive educational environment?

\section{Readiness of Special Education Specialists}

The analysis of the scientific fund on the issue of readiness of special education specialists reflects various aspects: theoretical-methodological and philosophical bases of inclusive education (J. Deppeler, D. Harvey, T. Loreman, A. Kolupaeva, V. Sinyov, O. Taranchenko); pedagogical bases of training of higher education specialists (V. Andrushchenko, I. Zyazyun, V. Kremen); ways of professional training and retraining of personnel for special education (M. Alyokhina, I. Demchenko, A. Kolupaeva, I. Malyshevskaya, N. Pakhomova, V. Khytryuk, Z. Shevtsiv, M. Sheremet, etc.); interaction between specialists of the psychological and pedagogical support of inclusive education team (I. Dmitrieva, I. Kuzava, O. Martinchuk, S. Mironova, Y. Naida, L. Savchuk, N. Sofiy, etc.)

N. Sophiy [18] defined the team approach as determinative, the degree of implementation of which depends on the level of quality of comprehensive assistance to children with special educational needs.

A significant role in the exercise of corrective influence on a child with severe speech disorders is assigned to a speech therapist. He conducts educational and corrective work with children with speech defects, diagnoses and records the state of speech development of children, and corresponding dynamics of their speech development. At the same time, in order to develop the optimal pedagogical strategy, and to find the optimal individual educational trajectory of the child-speech therapist, the speech-therapist should work jointly with other specialists. Here at the stage of training of special staff there is a question of readiness of future speech-language teachers for team interaction in the conditions of inclusion, and their awareness of professional duties in the new conditions.

The effectiveness of development of communicative competence of specialists of the team of psychological and pedagogical support of inclusive teaching was proved by O. Dmitrieva, T. Dokuchina [8]. The training was attended by 60 people from the inclusive educational institutions of Kamianets-Podilskyi. The purpose of the training was to bring the participants together into a single, coordinated team in order to efficiently solve their tasks and develop their communicative competence. I. Dmitrieva [7] in her research concluded that the team approach in inclusion ensures the integrity of all efforts to include the child in the educational space.

Z. Leniv [12] examined the formation of the cognitive-competence component of the professional readiness of special education specialists to implement a team-individual approach in the inclusive education of children with special educational needs. The experiment involved 1250 students - future teachers' assistants. The results obtained by the researcher showed the need to improve the system of training of teaching assistants in higher education institutions.

The paper of Lani Florian and Holly Linklater [9] reports findings of a study of a new initial teacher education course that starts from the premise that the question is not whether teachers have the necessary knowledge and skills to teach in inclusive classrooms, but how to make best use of what they already know when learners experience difficulty.

According to many researchers [7, 23], providing assistance to teachers involved in inclusive education is a key requirement for successful inclusion. Here, it is important to bring all inclusive school professionals together into inclusive teams, equally interested in the collaboration of the administration and the teachers.

Despite the significant number of scientific works on the training of special education specialists, researchers do not pay enough attention to the purposeful training of special education specialists (including speech therapists) for team interaction in the conditions of inclusion.

The need for research is emphasized by the presence of a number of contradictions: between the public's demand for teamwork and the lack of knowledge, skills and abilities of teachers on teamwork; between the modern requirements for a graduate of a higher education institution and the lack of a model for forming a specialist 
ready for teamwork in an inclusive environment.

\section{Methodology}

\subsection{Research Design}

Our research was carried out by means of theoretical (analysis, synthesis, classification, systematization and generalization of scientific works on the training of special education specialists), empirical (analysis of students' activities in training, interviews, questionnaires, focus group, pedagogical evaluation), statistical (descriptive statistics for processing the obtained data and establishing the scientific reliability of the research results), graphical (construction of graphs and tables for visual illustration of the results of the experimental parts and research) methods.

The research methodology can be attributed to a mixed type that integrates qualitative and quantitative approaches. A complementary type of component design is used where the results obtained by the basic method are specified and refined based on the results obtained by the methods of minor importance. In our study, the main method of questioning was chosen, the secondary one was the focus group method. The study involved data collection, statistical analysis.2.4. Figures

\subsection{Sampling}

The sample of respondents was formed on the basis of purposeful random selection. In order to determine the level of readiness for team interaction, we conducted a study among students of day and correspondence forms of study at such specialties as "Special education (speech therapy)", "Primary education. Inclusive education", "Preschool education. Speech Therapy" at Izmail State University of Humanities, and "Correctional Education. Speech Therapy", "Preschool Education. Speech Therapy" at South Ukrainian National Pedagogical University named after K.D. Ushynsky. A total of 106 people participated in the study.

At the beginning of the experiment, control (CG) and experimental (EG) groups were formed, the homogeneity of which was checked by Student's t-test.

\subsection{Instruments}

The survey tool used in this study was a questionnaire. The survey group was asked questions: open and closed, direct and indirect. This method has provided high comparability of information and ease of processing. The questions were asked in such a way as to determine the level of formation of the components of readiness of future specialists of special education for team work in the conditions of inclusion, namely motivational-personal, cognitive, activity-creative, reflective, inclusive. The analysis of quantitative data was carried out according to the frequency of response (percentages determined), indicators of readiness for teamwork on the scale of evaluation was determined.

The qualitative approach of the study was provided by the method of focus groups.

\section{Results and Discussion}

The results of the observational stage of the experiment showed that a high level of readiness for teamwork in the conditions of inclusion had $2 \%$ of future specialists in special education CG, no such level was found in EG; $47 \%$ of CG respondents and $50 \%$ of EG respondents had a medium level, $51 \%$ of CG and $50 \%$ EG had a low level.

The results of the study showed the average level of students' readiness for team practical training of speech therapist in inclusive education. The study identified readiness indicators in several aspects:

- knowledge of the peculiarities of the activities of speech therapists in the conditions of inclusion;

- teamwork skills of future speech therapists.

It should be noted that the motivational-personal component of readiness for team interaction in the context of inclusion is better formed in the future specialists of special education, the worst is the reflective and inclusive components.

Consider this as an example of the results of the EG.

First of all, it should be noted that $98 \%$ of those surveyed have an interest in a future profession, motivated to pursue a successful professional activity, and seek to help children with speech defects. From the first year of study students understand the need for improvement in the profession throughout their lives and creative approach to solving professional tasks.

Among the functions of speech therapist, $50 \%$ of respondents identify corrective as the main, $34 \%$ of respondents add more communicative and psychological functions, which determine how to help children become comfortable in the outside world. $16 \%$ of respondents did not think at all about the functions of a speech therapist.

$70 \%$ of respondents have a value-terminological spectrum regarding inclusive education.

Awareness level at 10 points (12-point scale) is determined by $40 \%$ of respondents, at 9 points $-35 \%$, at 8 points $-25 \%$. 


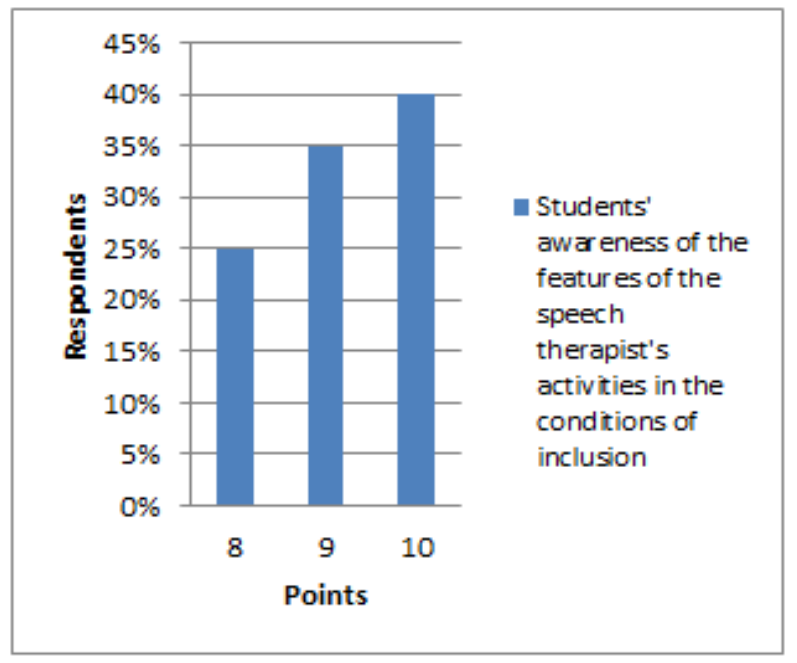

Figure 1. The result of students' awareness of the features of the speech therapist's activities in the conditions of inclusion

The cooperation of the speech therapist with other specialists involved in creating an inclusive educational environment is considered positive by all respondents. However, only $34 \%$ of respondents are aware of the extension of teamwork. There are some differences in the definition of the subjects of the interaction team. For example, other specialists of special profile include $30 \%$ of respondents, specialists and parents - $40 \%$ of respondents, add to the list of employees, $50 \%$ of respondents determine the degree of their readiness for teamwork at the level of 8 points, $34 \%$ - at the level of 6 points, $16 \%$ - at the level of 7 points.

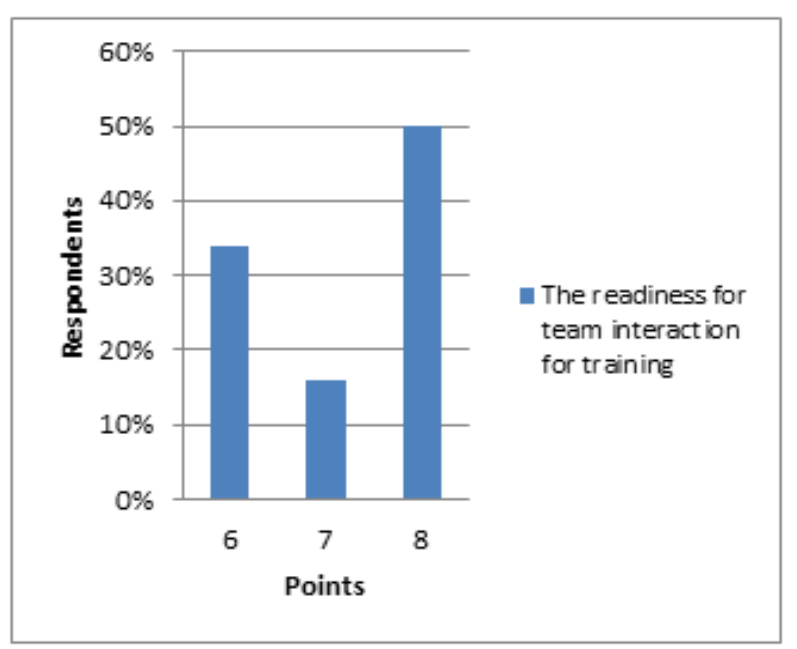

Figure 2. The result of the readiness for team interaction for training

These results indicate a lack of readiness for future speech therapists to engage in team interaction in an inclusive environment. It is especially important to emphasize the unpreparedness of the young specialist to communicate with the family of the child-logopath. Although a strong scientific and methodological fund of training techniques, coaching technologies of student-centered training of future specialists in the context of the idea of "learning by engaging" is currently emerging, the question of students' ability to develop a strategy for interaction with a family of a categorical child remains problematic (Kichuk, 2019: 60).

The analysis of the obtained data allows us to predict and plan the educational activities of the future specialist in special education (speech therapist), to improve the pedagogical conditions for the professional preparation of students for team interaction in the context of inclusion. The definition of pedagogical conditions was carried out using L. Gutman's scale analysis. These conditions include: the development of positive motivation of higher education applicants for the implementation of team work in the process of professional activity; the direction of the process of forming professional competence of students on the ability to constructively fulfill the personal and professional functions of teamwork by enriching the content of professional training; providing student-centered learning in a higher education institution through the involvement of interaction resources.

The first condition we have highlighted contributes to the understanding by future speech therapists that the idea of inclusion is implemented provides the humanization of modern education.

The condition for enriching the content of vocational training that we singled out is provided by author solutions.

Thus, in our opinion, to prepare future speech therapists for team interaction in the context of inclusive education is possible through the introduction of such free choice disciplines as "Pedagogical bases of preparation of speech therapist teacher for team interaction in the system of inclusive education", and non-credit practical and training course "The Training for Team Interaction in the Conditions of Inclusion".

During the study of these courses, students realized the relevance of team interaction, worked out the conceptual apparatus "team", "team interaction", "partnership", etc., and also mastered theoretical and practical knowledge using the forms and methods of work to form the future specialist's readiness for team work in conditions of inclusion.

The third pedagogical condition - providing student-centered learning through the involvement of interaction resources was supported using the methods "Work in triples", "Joint project", "Synthesis of thoughts", "Role-playing game", "Take a position", "Change a position", which were intended to establish partnerships between participants, to familiarize students with the methods of distribution of roles, teach to make a joint decision and subordinate their actions to a common goal.

We have developed and tested a training aimed at shaping the readiness of future speech therapist teachers to work as a team, including the development of appropriate skills. The training was conducted in a group of students 
of the fourth course of specialty "Special Education (speech therapy)" at Izmail State University of Humanities. During the training, participants were to realize the need for common goals, define their team role, learn how to make decisions in a team, coordinate actions when achieving a result.

For this the training participants were offered business games, exercises and situations aimed at increasing trust, establishing partnerships between participants, introducing students to role-sharing, learning how to make joint decisions, and subordinating their actions to a common goal.

According to the results of the training and research by the method of questionnaire and focus group it was found that the level of readiness of future speech therapists for team interaction in the conditions of inclusive education increased. This is evidenced by quantitative indicators. In particular, $60 \%$ of respondents indicated their degree of readiness for team interaction at the level of 10 points, $25 \%$ - at the level of 9 points, $15 \%$ - at the level of 8 points.

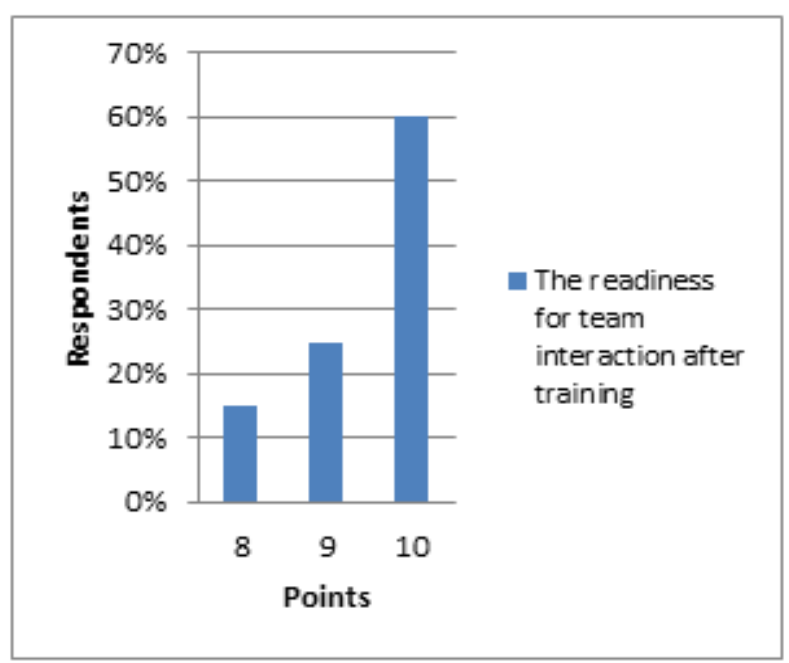

Figure 3. The result of the readiness for team interaction after training

The results of the readiness of future speech therapists in the EG for team interaction before and after the training are shown in Table 1.

Table 1. Readiness of future specialists for team interaction before and after training

\begin{tabular}{|l|c|c|c|}
\hline \multirow{2}{*}{ Readiness level } & & \multicolumn{2}{|c|}{ Number of respondents (percent) } \\
\cline { 2 - 4 } & & Before & After \\
\hline \multirow{3}{*}{ High } & 10 & 0 & 60 \\
\cline { 2 - 4 } & 9 & 0 & 25 \\
\hline \multirow{4}{*}{ Medium } & 8 & 50 & 15 \\
\cline { 2 - 4 } & 7 & 16 & 0 \\
\cline { 2 - 4 } & 6 & 34 & 0 \\
\cline { 2 - 4 } & 5 & 0 & 0 \\
\hline \multirow{5}{*}{ Low } & 4 & 0 & 0 \\
\cline { 2 - 4 } & 3 & 0 & 0 \\
\cline { 2 - 4 } & 2 & 0 & 0 \\
\cline { 2 - 4 } & 1 & 0 & \\
\hline
\end{tabular}

The results of the pedagogical experiment were interpreted for the Student's t-criterion in which data give reason to believe that the results of the experiment are not accidental, but provided by the implementation of selected pedagogical conditions.

\section{Conclusions}

The study found that future special education students are mediocrely willing to work as a team in inclusive education. Preparing them for teamwork is a purposeful process, focused on the ability to constructively fulfill the personal and professional functions of teamwork, and implementing an inclusive education model. It requires the creation of specific pedagogical conditions and the search for new forms and methods of work. The effectiveness of increasing the level of readiness for team interaction in the conditions of inclusion has been shown by the training we have developed, but it is only one way of preparing pedagogical workers of special education for team work, which, however, does not claim to be exhaustive. The author's technique implemented in the experimental group showed efficiency in increasing the level of readiness for team interaction in the conditions of inclusion. Further research is aimed at finding other ways of forming teachers' readiness to work in the conditions of inclusion.

\section{REFERENCES}

[1] Andrews, J., Lupart, J. The inclusive classroom: Educating exceptional children, Ontario: Nelson, Canada, 2000.

[2] Ben Yehuda S., Leyser Y., Last U. Teacher educational beliefs and sociometric status of special educational needs (SEN) in inclusive classrooms, International Journal of Inclusive Education. Vol. 14. No.1. 17-34.

[3] Buletin Anjakan Bil 5/2015. Kementerian Pelajaran Melaysia.

[4] Deppeler J., Loreman T., Smith R. Teaching and learning for all, Inclusive pedagogy across the curriculum. International perspectives on inclusive education, Vol. 7, 1-10.

[5] Deppeler, J., Loreman, T., Sharma, U. Reconceptualising specialist support services in inclusive classrooms, Australasian Journal of Special Education, Vol.29, No.2, 117-127.

[6] Dmitriyeva I. V. Team interaction of specialists in the process of individual support of the child in the conditions of inclusive learning. Actual problems of the correctional education, Vol.8, No.1, 29-39.

[7] Dmitrieva O. I., Dokuchina T.O. Development of communicative competence of correctional educators by means of team interaction training, Actual problems of the correctional education, Vol.11, Online available from 
http://aqce.com.ua/vipusk-n11-2018/dmitrijeva-oi-dokuchin a-to-rozvitok-komunikativnoi-kompetentnosti.html

[8] Florian L., Linklater H. Preparing teachers for inclusive education: using inclusive pedagogy to enhance teaching and learning for all, Cambridge Journal of Education, Vol.40, 369-386.

[9] Kichuk N. V. The problem of the future specialist's ability to interact with parents as a type of partnership in inclusive education, Social partnership in inclusive education: acmeological foundations, modern realities, 60-64, 2019.

[10] Kolomoets T. G. Interaction of specialists and parents of children with special education needs in conditions of inclusive education, Actual problems of the correctional education, Vol.14, 115-125.

[11] Leniv Z.P. Formation of professional readiness of specialists to work in the inclusive educational space of elementary school, Horizons: Scientific and Pedagogical Journal, Vol.2, No. 47, 57-61.

[12] Lingo A. S., Barton Arwood S. M., Jolivette K. Teachers working together: Improving learning outcomes in the inclusive classroom 6 practical strategies and examples, Teaching Exceptional Children, Vol.43, No.3, 6-13.

[13] Martynchuk, O.V. The content and structure of the professional competences of the future teacher-speech therapist, Pedagogical Education: Theory and Practice. Psychology. Pedagogics, No.24, 77-83.

[14] Poh Huoy Tyan, Fadzilah Abd Rahman, Maryam Shafie Sarvestani.Teachers' Readiness in Implementing and Facilitating 21st Century Learning, Universal Journal of Educational Research, Vol.8, No.1A, 24-29.
[15] Saloviita T. Special education and inclusion,Education. Vol. 37, No.4, 326-342.

[16] Snyder R. F. Inclusion: A qualitative study of in-service general education teachers' attitudes and concerns, Education. Vol. 120, No 1, 173-180.

[17] Sophiy, N.Z. Organizational-pedagogical conditions of integrated support of students with special educational needs in an inclusive educational institution. Abstract dissertations... candidate of pedagogical sciences: 13.00.03. Ukraine, 2017.

[18] Taranchenko O., Kolupayeva A., Danilavichute E. Special Education Today in Ukraine, Special Education International Perspectives: Practices Across the Globe, Vol. $28, .311-351$.

[19] Teacher Education for Inclusion. Profile of Inclusive Teachers. European Agency for Development in Special Needs Education, Online available from https://www.european-agency.org/sites/default/files/Profileof-Inclusive-Teachers.pdf

[20] Zhurenko, L.O. Formation of professional competence of the future teacher of a preschool institution at a pedagogical university, Higher and secondary schools in the context of modern challenges: materials of the International Scientific and Practical Conference, 150-154, 2016.

[21] Waldron N. L., Mc Leskey J., Redd L. Setting the direction: The role of the principal in developing an effective, inclusive school, Journal of Special Education Leadership, Vol. 24, No.2, 51-60.

[22] Waldron N. L., Redd L. Providing a full circle of support to teachers in an inclusive elementary school, Journal of Special Education Leadership, Vol. 24, No.1, 59-61. 